\title{
COVID-19 Outbreak in Pakistan; a Situational Analysis
}

\section{Nadia Noreen ${ }^{1, *}$, Sarmad Wahaj Siddiqui ${ }^{2}$, Saeed Ullah Khan Niazi ${ }^{3}$, Farida Khudaidad ${ }^{4}$, Naveed Ullah Khan ${ }^{5}$, Saima Dil $^{6}$, Mumtaz Ali Khan ${ }^{7}$ and Irum Naveed ${ }^{8}$}

${ }^{1}$ Team Lead/FELTP alumnus Covid-19 response Team, IIAP, Directorate of Central Health Establishments, Islamabad, Pakistan ${ }^{2}$ Manager, Epidemic prevention and Control Punjab, Primary\& Secondary Healthcare Department, Punjab, Lahore, Pakistan

${ }^{3}$ Joint Secretary (admin), Ministry of National Health, Regulations, Services \& Coordinations, Khosar Block, Islamabad, Pakistan

${ }^{4}$ Assistant Professor, community Medicine Department, Bolan University of Medical \& Health Sciences, Quetta, Pakistan

${ }^{5}$ Surgeon, Federal Government Polyclinic Hospital, Islamabad, Pakistan

${ }^{6}$ Deputy Director, Livestock \& Diary Department, Punjab, Rawalpindi, Pakistan

${ }^{7}$ Senior Scientific Officer, Federal Disease Surveillance Division, NIH, Islamabad, Pakistan

${ }^{8}$ Deputy Director OPD, Pakistan Institute of Medical Sciences, Islamabad, Pakistan

*Corresponding author: Nadia Noreen, Team Lead/FELTP alumnus COVID-19 response Team, IIAP, Directorate of Central Health Establishments, NIH Islamabad, Pakistan; E-mail: nadia.jamil3@gmail.com

Received: 01 Jun, 2020 | Accepted: 18 Jun, 2020 | Published: 27 Jun, 2020

Citation: Noreen N, Siddiqui SW, Niazi SUK, Khudaidad F, Khan NU, et al. (2020) COVID-19 Outbreak in Pakistan; a Situational Analysis. J Emerg Dis Virol 5(2): dx.doi.org/10.16966/2473-1846.153

Copyright: (C) 2020 Noreen N, et al. This is an open-access article distributed under the terms of the Creative Commons Attribution License, which permits unrestricted use, distribution, and reproduction in any medium, provided the original author and source are credited.

\begin{abstract}
The corona virus disease 2019 (COVID-19) caused by Severe Acute Respiratory Syndrome Corona Virus-2(SARS-COV-2), that emerged in China, Wuhan, in December 2019, has upended the world, with spread to 216 countries to-date, infecting 5,931,963 people and killing more than 365,051 persons and $2,496,857$ recoveries in almost five months. Pakistan reported its first two confirmed cases among religious pilgrims on $26^{\text {th }}$ February 2020 having the travel history of Iran.
\end{abstract}

Methods: It was a descriptive retrospective study using the publicly available data on cumulative confirmed COVID-19 cases, active cases, deaths, and recoveries from $26^{\text {th }}$ February to $29^{\text {th }}$ May 2020. The objective was to analyze the overall outbreak situation across Pakistan. The literature search strategy was through keywords on Pub-med and Google databases. Data analysis was done as descriptive statistics as percentages and frequencies using Epi info version 7 and Microsoft Excel 10 statistical components.

Results: The number of confirmed cases nationwide stands at 66,457 on $29^{\text {th }}$ May 2020 with 26,113 cases in Sindh, 4,104 in Punjab, 9,067 in Khyber Pakhtunkhwa (KPK), 4087 in Baluchistan, 2192 in Islamabad Capital Territory (ICT), 660 in Gilgit Baltistan (GB), and 234 in Azad Jammu \&Kashmir (AJK). The current CFR is $2.1 \%$. The highest number of deaths was reported from Khyber Pakhtunkhwa (445) with a crude fatality rate of $4.9 \%$. Currently, case and death doubling time was 15 days, a total of 1945 healthcare workers (3\%) are affected with 21 fatalities. To date $74 \%$ of confirmed COVID cases are males and $25.9 \%$ are females. The highest number (22.5\%) of confirmed cases from the age group of 20-29, highest deaths $(29.8 \%)$ is in the age group of 60-69 years. Local community transmission is reported to be $92 \%$.

Conclusion: Large scale outbreak has exposed the gaps in the underlying healthcare system. A very high population density, lack of public awareness, weak healthcare system, the resistance created by community dynamics, local and religious beliefs are making the containment of virus a tough challenge in Pakistan. COVID-19 will have long-lasting health and economic effects beyond morbidity and mortality caused directly by the virus itself.

Keywords: COVID-19; Community transmission; Population density; Community dynamics; Lockdown

Abbreviations: SARS-COV-2: Severe Acute Respiratory Syndrome Corona Virus-2; USA: United States of America; COVID-19: Coronavirus Disease-19; R-0: Basic Reproduction number; FDA: Food and Drug Administration; UK: United Kingdom; DRAP: Drug Regulatory Authority of Pakistan; CP: Convalescent Plasma; GHSA: Global Health Security Agenda; ICMS: Incident Command and Control/Incident Management System; ICU: Intensive Care Unit; NEOC: National Emergency Operation Cell; WHO: World Health Organization; EMRO: East Mediterranean Region; ICT: Islamabad Capital Territory; KPK: Khyber Pakhtunkhwa; AJK: Azad Jammu \& Kashmir; IPC: Infection Prevention Control protocols; POE: Point of Entry; ILO: International Labour Organization; PCR: Polymerase Chain Reaction; CFR: Crude fatality Rate; HCW: Healthcare Workers; TTQ: Trace Test and Quarantine; GDP: Gross Domestic Product; SOP's: Standard operating procedures; PPE: Personal Protective Equipment; EMRO: East Mediterranean Regional Office; UK: United Kingdom; NHS: National Health System 


\section{Introduction}

The corona virus disease 2019 (COVID-19) caused by Severe Acute Respiratory Syndrome Corona Virus-2 (SARS-CoV-2), which emerged in a China Wuhan, in December 2019 now a global pandemic has upended the world. With spread to 216 countries to date, infecting $5,931,963$ people and killing more than 365,051 persons and 2,496,857 recoveries in almost five months span [1]. Though the deadly epidemic has been contained in Wuhan the first origin and epicenter of SARsCOV-2 and elsewhere in China, the virus is doing havoc across Europe and the United States. The Americas with 2,613,092 confirmed cases is the worst affected continent. Europe has the highest death counts with 178,378 deaths. So far USA is leading with $1,747,087$ cases and 102,836 deaths followed by Brazil and Russia with 465, 166, and 387,623 cases respectively [2].

The COVID-19 disease is caused by a single-stranded RNA virus, SARS-COV-2. This new coronavirus which has not been previously identified in humans emerged in Wuhan in patients with severe pneumonia having links to the local seafood and live animal market. Evidence suggests the zoonotic source of SARS-CoV-2 with origin linked to bats $[3,4]$. The median incubation period for SARS-COV-2 is about 5.1 days (2-14 days average). The clinical illness is characterized by a long, mild prodrome lasting for the last 5- 9 days, with the highest load of viral shedding even with mild symptoms, increasing the risk for community transmission $[4,5]$. As per recent research, $80 \%$ of the infections are mild, $18.5 \%$ requiring hospitalization out of which 4.7 $\%$ will need critical intensive care unit (ICU) care [6,7].

The mortality rate of the COVID-19 is currently estimated at $6.5 \%$ globally [1]. The recovery rate is almost $42 \%$ [2]. The basic reproduction number $(\mathrm{R}-0)$ of the virus was $2-5$ but recent estimates indicate a high number between 4.7 to 6.6 [8]. No specific treatment for COVID-19 patients is yet approved, but the Food and Drug Administration (FDA) has recently authorized the emergency use of remdesivir, an experimental antiviral drug, to treat COVID-19 [9,10]. Almost 115 vaccine projects are in development with eight candidates initiated safety trials in people in the USA, United Kingdom (UK), China, and Australia [11]. Pakistan Pakistan's Drug Regulatory Authority of Pakistan (DRAP) has approved the passive Convalescent Plasma (CP) treatment for patients with serious COVID-19 infections [12]. The successful clinical trial of passive immunization has resulted in the recovery of a 53-year-old COVID patient marking a breakthrough for health authorities grappling with an outbreak. Eight health facilities in major cities across the country are approved for clinical trials and have started plasma collection from patients recovered from the coronavirus [13].

Pakistan with a unique challenge of highly porous borders is sandwiched between the first two epicenters of COVID-19, China, and Iran. Pakistan reported its first two index cases of coronavirus on $26^{\text {th }}$ February 2020 traced to Iran-the the worst virus hit the country in the Middle East [14]. Despite the proximity to China, not a single case of the virus was imported from China. Directing of pilgrims from Iran back to their cities without proper testing resulted in the introduction of the virus in the country [15]. After a brief hiatus following the first case, the number of confirmed cases in Pakistan soared in mid-March largely driven by a wave of pilgrims returning from Iran who were inadequately tested and improperly isolated and quarantined due to lack of proper facilities at Taftan land crossing $[15,16]$. Other cases were reported linked with the travel of Syria, the UK, and Saudi Arabia [17]. Local community transmission started in Mid-March from Karachi in a 20 years old boy with no recent travel history [18]. Community transmission is now widespread with $92 \%$ of all confirmed cases due to local spread [19]. Local transmission of COVID-19 is intensifying further as people are not strictly following social distancing protocols and preventive measures.

The government of Pakistan gave a National Preparedness \& Response Plan for COVID-19 as a blueprint for Pandemic Preparedness for Pakistan under Global Health Security Agenda (GHSA) in March, 2020 to cope with Coronavirus outbreak in the country [20]. Incident Command and Control/Incident Management System (ICMS) along with National emergency operation Cell (NEOC) for COVID-19 response were established to monitor the daily situation of the outbreak. Policy frameworks were drafted for federal, provincial, and regional stakeholders to build capacity to prevent, detect, and respond to the confirmed cases of COVID-19 in Pakistan. Advisories are being continuously issued to all relevant stockholders for taking necessary measures and are being revised from time to time according to the evolving situation.

Pakistan is the second hardest-hit country in South Asia, with the third-highest cases in the WHO categorized EMRO region after Iran and $18^{\text {th }}$ highest case count globally [21]. The confirmed cases count has ascended to 66,457 across the country with Punjab and Sindh the most hard-hit province [22]. The number of cases has continued to soar despite the country being under partial lockdown for the ninth consecutive week. The situation remains highly fluid with stats changing at a fast pace. This study aimed to analyze the COVID-19 cases and the overall outbreak situation across Pakistan.

\section{Methods}

It was a descriptive retrospective study using the publicly available data on COVID-19 total and active cases, deaths, recoveries from Ministry of National Health Services Regulations and Coordination COVID-19 dashboard and provincial governments official social media platforms from $26^{\text {th }}$ February to $29^{\text {th }}$ May 2020 to see the current situation of COVID-19 among Pakistani population. Data analysis was done as descriptive statistics as percentages and frequencies using Epi info version 7 and Microsoft Excel 10.

Literature searching of the PubMed electronic database and google was undertaken using the keywords "novel coronavirus", "COVID-19", "Pakistan", "COVID pandemic", "community transmission" in various permutations and combinations.

\section{Results}

The increased influx of travelers through air, and land route, facilitated the importation of viruses. Pakistan reported its first two confirmed cases among religious pilgrims on $26^{\text {th }}$ February 2020 having the travel history of Iran [14].

The number of confirmed cases nationwide has risen to 66,457 on $29^{\text {th }}$ May 2020 with Sindh and Punjab province with the highest number of cases. Sindh is the worst-affected province in the outbreak, with the daily surge in the number of cases reported from Punjab. So far 26, 113 tested positive in Sindh, 24,104 in Punjab,9,067 in Khyber Pakhtunkhwa, 4,087 in Baluchistan, 2192 in Islamabad Capital Territory (ICT), 660 in Gilgit Baltistan (GB), and 234 in Azad Jammu \& Kashmir (AJK) [22]. The situation is quite emerging and alarming with a surge in daily cases at a rapid pace. Table 1 shows the COVID-19 related statistics [23] Figure 1 illustrates the location of COVID cases across country(source Covid.gov.pk).

Initially, at the start of the outbreak in late February, 2020 the testing by Polymerase Chain Reaction (PCR) for SARS COV-2 was very limited and only symptomatic with travel history of high-risk countries were 


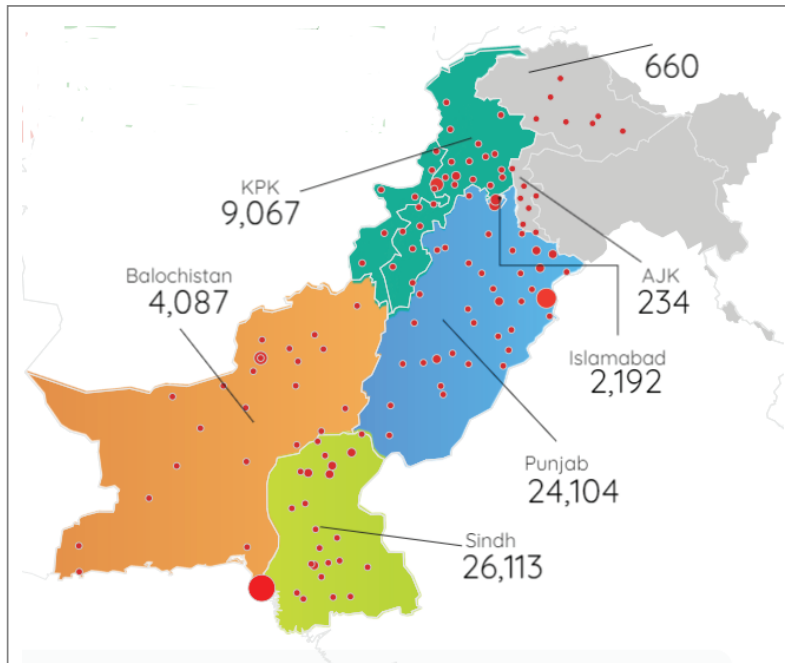

Figure 1: Spot Map of Covid-19 (Covid.gov.pk). tested. Pakistan witnessed a constantly increasing trend in the daily confirmed cases from mid-March 2020 owing to an increase in testing and the start of community spread. Strict nationwide lockdown along with border closure and suspension of international flight operations was imposed w.e.f $23^{\text {rd }}$ March 2020 which resulted in a slow steady spread of infection. Despite the surging number of Coronavirus cases government announced a gradual ease of five weeklong lockdown from $25^{\text {th }}$ April, 2020 citing a flailing economy and high poverty rates with strict implementation of social distancing guidelines. The relaxation resulted in an abrupt increase in daily cases with a 5 -fold increase in infection count. Figure 2 shows the daily reported COVID-19 cases with clear visualization of case count before imposition of lockdown, during lockdown and post lockdown phase.

Pakistan reached its first 100 confirmed cases on $16^{\text {th }}$ March 2020 twenty days after reporting the first case; the count reached 1000 cases on $24^{\text {th }}$ March 2020 within 28 days of first confirmed case, 10,000 , on $22^{\text {nd }}$ April 2020, after 57 days of a first confirmed case, 20,000 on $3^{\text {rd }}$ May, 2020, 68 days after first reported case. The tally now stands at 66457 cases after 94 days of the start of the outbreak.

\section{Case doubling rate}

After reporting of first two cases on $26^{\text {th }}$ February 2020, it took 20 days to reach the first hundred cases, the case doubling time was 3 days initially after the first cases then it was reported as seven days till $5^{\text {th }}$ April 2020. Doubling time remained at 10 days for four weeks till $6^{\text {th }}$ May 2020. Currently doubling rate stands at 15 days despite of sudden surge in daily reported cases. The doubling time is dynamic and gives information regarding the impact or lack of impact of interventions on epidemic growth. The graph in figure 3 is the graphical presentation of the doubling rate of COVID-19 cases in days.

Pakistan reported its first two deaths on $18^{\text {th }}$ March 2020, with a clinical Case Fatality Rate (CFR) of $0.6 \%$ which doubled to $1.3 \%$ on $30^{\text {th }}$ March in twelve days. The current CFR is $2.1 \%$. The country witnessed the highest rise in deaths in a single day with 78 deaths in COVID-19 confirmed cases on $29^{\text {th }}$ May 2020. The current death doubling rate of COVID-19 deaths is 15 days. The graph in figure 4 describes the CFR doubling rate since the country reported its first five deaths on $5^{\text {th }}$ March 2020.

Regarding gender, $77.5 \%$ confirmed COVID-19 cases were males and $22.5 \%$ were females. The most affected age group was from the younger age group (20-29 Years of age) with $21.5 \%$ of confirmed cases. Highest deaths were in males and from age group of 50-59 years (42.9\%). The graph in figure 5 is showing the demographic details of COVID-19 cases in Pakistan.

COVID-19 outbreak is now mostly of local transmission with $92 \%$ of cases accounting for community spread [19].

\section{The province-wise details are as follows}

Sindh: COVID outbreak in Pakistan started from Sindh with reporting of the first case on $26^{\text {th }}$ February. Initially, all the cases were imported with the first case of local transmission was reported on $16^{\text {th }}$ March 2020. With 26,113 confirmed positive cases and involvement of 24 districts, Sindh is the worst effected province with the highest number of cases and deaths reported from Karachi the provincial headquarter with the highest rate of community transmission. Karachi is on increase in terms of daily new cases and deaths since the last week of April 2020. The percentage positivity of tests conducted stands at $24.2 \%$. 


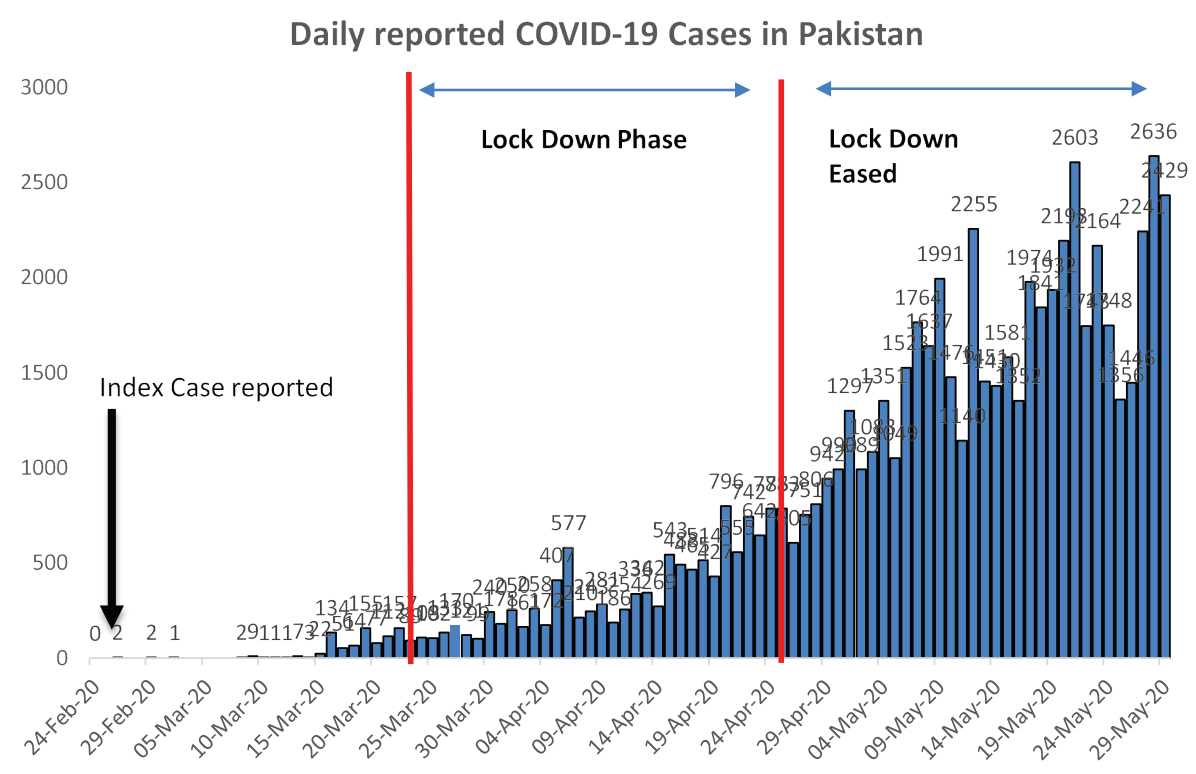

Figure 2: Daily New COVID-19 Cases in Pakistan.

\section{Doubling Rates of Reported Covid-19 Cases in Pakistan}

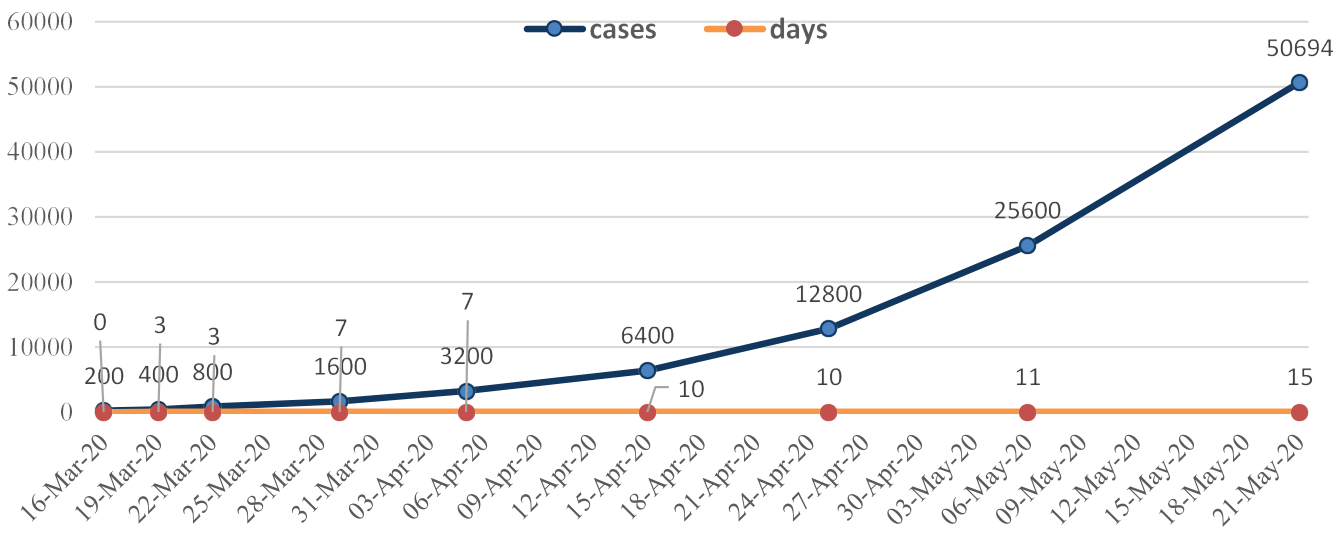

Figure 3: Doubling Rates of Reported Covid-19 Cases in Pakistan in days.

Punjab: Punjab the most densely populated province in the country is one of the hardest-hit provinces with 36 districts affected. Lahore the provincial capital tops with 11,339 cases. Confirmed cases are grouped into four categories Zairian, Tablighi Jamaat cohorts, prisoners, and community. A large number of coronavirus cases have been confirmed in government congregation setup. Many of the infected officials included were posted on points of public dealing like pickets, Ehsaas Programme, quarantine centers, and hospitals.

Table 2 provides detailed statistics on the COVID-19 cases, source, community transmission breakup, testing capacity and healthcare facilities, and usage among provinces and federal capital.

Khyber Pakhtunkhwa (KPK): Khyber Pakhtunkhwa (KPK) with the involvement of 35 districts has 9,067 confirmed cases and 445 deaths with the highest CFR of $4.9 \%$. Peshawar and Mardan are the worst effected districts with the highest healthcare capacity utilization. Swat is the second city with the highest deaths (41) after the provincial capital (255). The majority of positive patients are of the age group 50 to 59 years old. The government is conducting 1486 tests per million people, which is significantly lower than other provinces [24].

Baluchistan: Baluchistan is the area wise the biggest province of Pakistan. Initially the quarantine place at Taftan lacked proper facilities. Lack of doctors and other basic facilities with squalid living conditions at the camp and close contact conditions during quarantine due to lack of enough space resulted in multiplied infections at the Taftan facility [15]. Twenty-three districts out of 30 are effected with the COVID-19 outbreak with the highest number of cases (3350) and deaths reported from Quetta the provincial capital. Quetta reports the 
Covid-19 CFR doubling Rate in Pakistan(days)

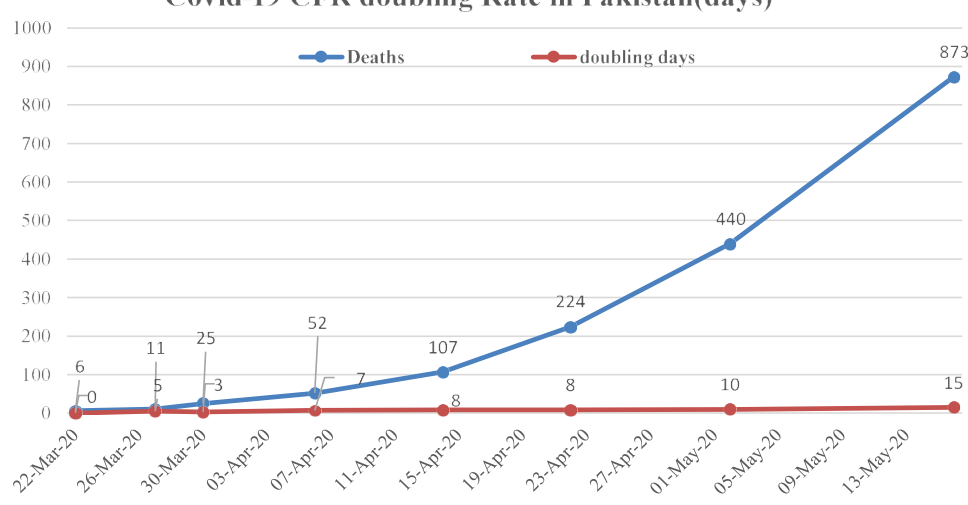

Figure 4: CFR doubling rate in days.

Age-wise and Gender Breakup of Covid-19 confirmed cases

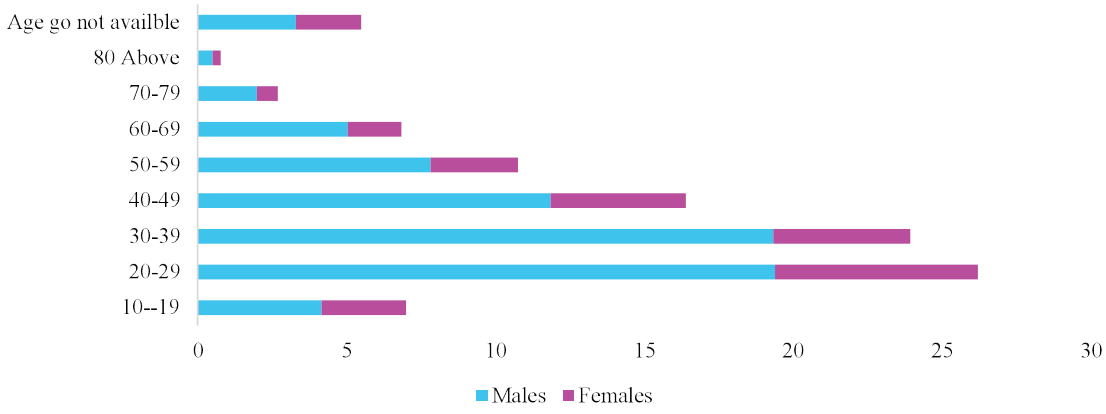

Figure 5: Age-wise and Gender wise Breakup of COVID-19 confirmed cases (Covid.gov.pk).

Table 2: Province wise detail of COVID19 cases [19].

\begin{tabular}{|c|c|c|c|c|c|c|c|}
\hline & Sindh & Punjab & Baluchistan & KPK & GB & ICT & AJK \\
\hline Confirmed Cases & 26113 & 24104 & 4087 & 9067 & 660 & 2192 & 234 \\
\hline Total Tests done & 171222 & 228415 & 23394 & 52721 & 8257 & 37728 & 5975 \\
\hline Tests Per Day & 3316 & 5341 & 753 & 1214 & 144 & 1015 & 237 \\
\hline Test per million population & 2306 & 3326 & 1750 & 1486 & 6162 & 31930 & 1320 \\
\hline Quarantined & 11902 & 14733 & 2555 & 5454 & 50 & 1962 & 0 \\
\hline \multicolumn{8}{|l|}{ Imported Cases: } \\
\hline Religious Zairean (Iran) & 280 & 768 & 146 & 77 & 166 & 0 & 2 \\
\hline Importation from other countries & 1232 & 1306 & 2 & 1227 & 5 & 22 & 13 \\
\hline \multicolumn{8}{|l|}{ Locally Acquired Infection: } \\
\hline Tablighi Jamaat & 767 & 1926 & 13 & 315 & 27 & 12 & 8 \\
\hline Others & 23834 & 20104 & 3926 & 7448 & 462 & 2158 & 211 \\
\hline Prisoners & 212 & 86 & - & - & - & - & - \\
\hline Total & 24601 & 22030 & 3939 & 7,763 & 489 & 2,170 & 219 \\
\hline Critical & 305 & 126 & 16 & 253 & 1 & 16 & 4 \\
\hline Deaths & 427 & 439 & 46 & 445 & 9 & 23 & 6 \\
\hline CFR & $1.70 \%$ & $1.80 \%$ & $1.10 \%$ & $4.90 \%$ & $1.40 \%$ & $1.00 \%$ & $1.70 \%$ \\
\hline Recoveries & 12,750 & 6,507 & 1,400 & 2,731 & 477 & 161 & 105 \\
\hline Recovery Rate & $48.80 \%$ & $27 \%$ & $34.30 \%$ & $30.10 \%$ & $72.30 \%$ & $7.30 \%$ & $45 \%$ \\
\hline Ventilator Usage \% & $40 \%$ & $25 \%$ & 0 & $34.50 \%$ & 0 & $12 \%$ & 0 \\
\hline Community Transmission & $94 \%$ & $91 \%$ & $96 \%$ & $86 \%$ & $74 \%$ & $99 \%$ & $94 \%$ \\
\hline
\end{tabular}


highest rate of local transmission (85.2\%). The most effected age group is $30-44$ years of age with $32.9 \%$ of total cases. The majority $(48.7 \%)$ of deaths are reported in 60 plus age group. As on $29^{\text {th }}$ May, 2020 Baluchistan has 4,087 confirmed cases with 46 deaths. Tests conducted per million population stands at 1750 per million so far [24].

Gilgit Baltistan: The majority of the pilgrims who returned from Iran at the start of the outbreak were residents of Gilgit Baltistan. The tally stands at 660 positive cases with 174 active cases the majority of them are males $(66.7 \%)$. All ten districts are involved with the highest cases reported from Gilgit (93). Local transmission is $74 \%$, which is lowest so far as compared to other provinces, along with the highest recovery rate of $(72.2 \%)$ [25].

Islamabad Capital Territory: Islamabad the federal capital has reported the highest percentage of community transmission i.e. $99 \%$ with $1 \%$ of imported cases. The tally stands at 2192 cases with 23 deaths with an alarming hike in the number of daily cases since $18^{\text {th }}$ May (100 plus cases daily) with the highest cases 151 reported on $27^{\text {th }}$ May, 2020. The majority of cases were male (67.7\%) with 31-45 years of age group, the most effected comprising $70 \%$ of confirmed cases. The surveillance and contact tracing strategy of test trace and quarantine(TTQ) is strictly implemented in Federal capital with $16.29 \%$ detection of positive cases by the TTQ method of testing among contacts $[26,27]$.

Azad Jammu and Kashmir: Azad Jammu and Kashmir have 93\% of community transmission with 234 confirmed,123 active cases, and six deaths as of $29^{\text {th }}$ May,2020.1320 tests per million population are conducted.

In addition to local transmission of the virus, another issue is the asymptomatic phenomenon which was first surfaced in Diamond Princess Cruise Ship quarantined aboard near Tokyo where $17.9 \%$ of cases were asymptomatic $[28,29]$. There are a growing number of asymptomatic patients (patients without symptoms) across Pakistan. As per the latest countrywide data, $80 \%$ of those tested positive do not display any symptoms. Khyber Pakhtunkhwa reports $70 \%$ such cases out of its total count, Baluchistan $85 \%$, Islamabad has an average of $83 \%$ asymptomatic cases, Punjab $82 \%$, and Sindh $80 \%$. The asymptomatic positive cases are responsible for the speedy local spread among the population as viral shedding is taking place [30].

\section{Healthcare workers}

Healthcare workers (HCWs) are always on the frontline with the greatest risk of exposure to infection. According to WHO report, and national figures 1945 healthcare workers are infected with COVID-19 through the country with the highest number effected in KPK with twenty-one confirmed deaths with eight deaths from Sindh, five from KPK, three in Punjab, two in GB and Baluchistan and one in Islamabad. There is an alarming increase in the number of infected health care workers in the country. Lack, inadequate availability and improper use of personal protective equipment (PPE) by front-line healthcare workers, non-following of infection prevention and control (IPC) protocols, inadequate training for IPC, long-time exposure to large numbers of infected patients directly increasing the risk of infection for healthcare workers, High workload, heightened anxiety fatigue, lack of rest and sleep are indirectly increasing the infection chances for healthcare workers. The graph in figure 6 shows the breakdown of positive cases among healthcare workers. Table 3 gives statistics regarding the outcome of infected healthcare workers.

Stranded Pakistani: All international flight operations were suspended w.e.f $23^{\text {rd }}$ March 2020, due to the worsening coronavirus

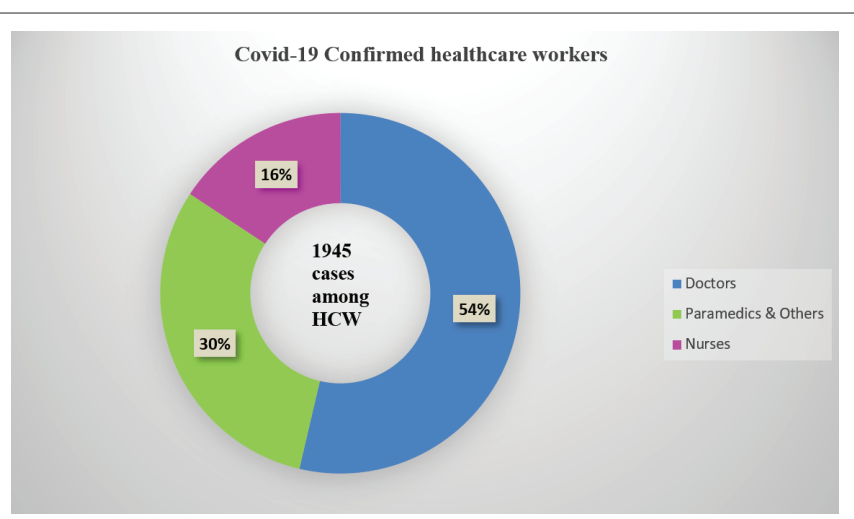

Figure 6: COVID-19 Confirmed healthcare workers [19].

Table 3: Status of COVID-19 confirmed Healthcare workers ( $n=1945)$ [19].

\begin{tabular}{|l|c|}
\hline Status of Health care workers & $\mathbf{N}=\mathbf{1 9 4 5}$ \\
\hline Isolation (home/Others) & 1042 \\
\hline Hospitalized & 181 \\
\hline Stable & 177 \\
\hline Critical (On Vent) & 4 \\
\hline Recovered & 701 \\
\hline Deaths & 21 \\
\hline
\end{tabular}

pandemic situation in the country and across the globe. Government of Pakistan has formulated a new health policy for stranded Pakistani traveling back to Pakistan through special flight operation w.e.f $15^{\text {th }}$ April 2020 with a special focus on Pakistani workers stranded in United Arab Emirates, Saudi Arabia, and Qatar. Strict implementation of all standard operating procedures (SOPs) including a mandatory 48-hour state-monitored quarantine period in government quarantine centers or paid hotel facility by choice of passengers. SARS-COV-2 PCR testing is done after 48 hours. Based on PCR results positive cases are isolated for 14 days from result date while those who test negative are advised compulsory self-quarantined to complete 14 days. Up to 29th May 2020, 313 flights have been operated with repatriating 33287 passengers to-date from 55 countries [31].

\section{Discussion}

Pakistan reached its first 100 confirmed cases in twenty days after reporting the first case. It took a month for Pakistan to confirm 1000 novel coronavirus cases. COVID-19 cases reached 10,000 on $22^{\text {nd }}$ April 2020 , after 57 days of first confirmed case. The count crossed 50,000 on $2^{\text {st }}$ May 2020, 86 days after the start of the outbreak. Comparing this with other countries the USA reached its 10,000 cases 58 days after reporting the first case on 22nd January and count has exceeded to 50,000 cases on $24^{\text {th }}$ March 63 days after reporting of a first confirmed case. Iran reported its first 10,000 cases 23 days after reporting the first case on $19^{\text {th }}$ February 2020 [32].

Pakistan witnessed a spike in cases from the first week of April 2020 as the country's testing capacity was increased along with reporting of positive cases among clusters of Tablighi jamaat. By the end of May, Pakistan had conducted over 508,086 tests with a $24 \%$ positivity percentage. KPK is conducting 1486 tests per million people, which is significantly lower than in other provinces. Whereas in Punjab, the 
total testing capacity stands at 1902 , Sindh at 3326 , AJK at 1320 per million, Baluchistan at 1750 per million, Gilgit Baltistan GB is 6162 and Islamabad stand highest with 31,930 tests per million [19]. For a population of more than 218 million, the country has conducted 55 tests per 1,000 people which are still far from mass testing levels to get a true picture of the epidemic [32]. In contrast, Malaysia has carried out 255, South Korea 213, New Zealand 850, United States 1167, Italy 1029 , while India has conducted 75 tests per 1,000 people and Australia, has conducted the highest 1270 tests per 1000 people [23].

1In mid-March 2020 after a steep surge in cases, lockdown with travel restrictions was imposed, and all public events were banned as a risk mitigation measure. Pakistan army troops were deployed starting, March 23, to help provincial governments effectively implement their measures to contain the coronavirus [33]. The government has failed to implement an effective strict lockdown. Sindh government was the first to announce lockdown in March, but the province is still battling the spread of the virus with the highest reported confirmed cases todate.

Pakistan with a population of 212.8 million is among the top five most populated countries in the world with a very high population density in several cities [34]. Pakistan has transitioned to an alarming state on COVID-19 within a month after ease of lockdown with a 5 -fold increase in COVID case. India witnessed a similar increase in cases at a faster rate with ease of restrictions nationwide [35]. The high population density in major cities of Pakistan and overcrowding is favoring the spread of the virus. Local transmission is equally increasing in rural and urban areas [30]. Karachi capital of Sindh is the worst affected province so far with the highest number of COVID 19 confirmed cases and highest reported local transmission, with a staggering 14.91 million population [34].

Mortality data is an accurate tool for portraying the real picture of the outbreak in the country. The reported case fatality rate of $2.1 \%$ in Pakistan is substantially lower than the global $6.2 \%$ and compared to the hardest-hit countries like Italy (14.3\%), United Kingdom (14.0 $\%)$, Spain (11.4\%), USA (5.9\%), and Iran (5.2\%) as of May $30^{\text {th }}, 2020$ [2]. Pakistan reported its first two deaths on $18^{\text {th }}$ March 2020, with a clinical case fatality rate (CFR) of $0.6 \%$ which doubled to $1.3 \%$ on $30^{\text {th }}$ March in twelve days. Highest reported CFR is $2.3 \%$ as of 2nd May 2020. The country witnessed the highest rise in deaths in a single day with 78 deaths among COVID-19 confirmed cases on $29^{\text {th }}$ May 2020 [20]. The abrupt increase in daily case count since the start of the third month of the outbreak (May) is accompanied by an increase in several daily deaths. The death Doubling rate of COVID-19 deaths is now 15 days. Comparing it with other worst effected countries reported the CFR doubling rate of India is 17 days, while it is 51 days for the USA, 39 days for the UK, 38 days for Turkey and globally, 51 days for Iran and Italy [36].

In Pakistan, the most affected age group is towards the younger side 20-29 years of age with $22.5 \%$ of reported cases. Pakistani population is the youngest population in the world with $65 \%$ under 30 years of age [34], one of the possible reasons for the high infection rate among this age group and low CFR. The said age group being the productive age group is the bread earners of family and is outdoors for work so are at the highest risk of exposure and contracting diseases. Pakistan has only $4 \%$ individuals of age 65 years or above that is considerably less compared to China (11\%), Us (16\%) Italy (22.08\%), Spain (19\%), and Iran (6\%) [37]. The age-wise mortality rate of $80-89$ years is highest at $20.75 \%$ as per WHO figures. The highest percentage of deaths is reported in the age group 60-69 years [22].
The COVID-19 impact on the Pakistani economy is estimated to be equivalent to $0.8-1.3 \%$ of the GDP $[38,39]$. The magnitude of national output losses due to pandemic ranges from Rs 891 billion to 1.6 trillion in the fourth quarter as per World Bank assessment [40]. The forecasted GDP down growth is $2.4 \%$ due to COVID-19 [41]. Pakistan's economy already surfaced mild recession and the COVID-19 crisis has forced Pakistan's already suffering economy to a grinding halt. The lockdown measures have negatively impacted the economy and society, particularly the vulnerable. Nearly onethird of the population is subsisting from daily and piece-rate wages in Pakistan [42]. The shutdown measures have already impacted the informal sector comprising of small businesses, small and medium enterprises, which account for a major share of the national economy and employ 27.3 million individuals [43]. An increase in unemployment and poverty coupled with implications on food production and overall food security due to supply chain disruption is anticipated. Twenty-four point three (24.3\%) percent of the Pakistani population is already living below the poverty line [44]. Most vulnerable populations regarding the enforcement of lockdown are the daily wage vendors and labor class. Poverty is rampant in the country, with poor people unable to make both ends meet, considering coronavirus as the least of their issues. Employment loss is estimated to $2.5 \%$ of the working force rendering 18.5 million people jobless [45]. COVID 19 pandemic impact will cause 195 million job losses which account for $37.5 \%$ of global employment as per international Labour Organization ILO analysis [47]. The cash payment program with an allocation of $\$ 900$ million to deliver one-time financial assistance to the 12 million families is being launched by the government. This programme is administered through Ehsaas programme-the federal government's new poverty alleviation programme, in partnership with all the federating units of Pakistan, to provide financial support to over 80 million people [47].

Pakistan is a resource-poor country with less than $1 \%$ of its GDP spending on healthcare and a weak health system with six hospital beds per 10,000 people is subject to catastrophic impact in case of an outburst of cases just like in Iran and Italy [48-50]. COVID 19 is likely to stress the capacity of the public health system. Baluchistan the largest province by area has a neglected healthcare system, which has remained under-resourced and understaffed. Large scale outbreak has exposed the gaps in the underlying healthcare system even challenging for the well-resourced health systems of the world as in the United Kingdom; National Health System (NHS) and USA [51]. As the pandemic continues to grip the country with widespread local transmission, the healthcare system appears to be crepitated under the strain. With an alarming increase in the number of infected health care workers, hospitals are struggling to safely provide care to patients while keeping their staff protected. Shortage of personal protective equipment (PPE) with a lack of training for proper use of PPE's and IPC protocols are one of the cause of these rising infections among healthcare workers. The government has devised a national program for the safety of healthcare workers along with the development of national guidelines for the use of Personal Protective Equipment (PPE's) [52]. So far 1945 health care workers (3\%) are infected with 21 deaths. Global figures have risen to 90,000 infected health care workers in 194 countries and 1000 deaths around the globe [53]. As per WHO report every one in ten health workers is infected with coronavirus in some worst effected countries like China, Italy, Spain, France, and the United States of America (USA) [54]. In Italy, according to a report published by the International Council of Nurses, $9 \%$ of the country's COVID-19 cases were healthcare workers [55]. United Kingdom (UK) has also reported high infection rates among healthcare workers with 
one in four National Health System (NHS) Doctors in the UK who are infected with COVID-19 [56].

At 66,457 cases Pakistan accounts for $1.1 \%$ of cases globally, $14 \%$ of cases of EMRO region and $27.9 \%$ of total cases in South East Asia, as compared to USA $29.5 \%$, Brazil $7.8 \%$, Italy $3.9 \%$ and Iran accounting for $2.5 \%$ of global cases although unreported infections are masking the true extent of the pandemic37. The recovery rate of COVID-19 is $36.3 \%$ in Pakistan 38 . When compared with global figures its $42 \%$ globally, $65.8 \%$ in Italy, $23.2 \%$ in the USA, and the highest rate is reported from Germany (89.8\%) [2].

The total COVID-19 cases in Australia, New Zealand, and Pakistan stand at 7185,1504 , and 66,457 , respectively. Pakistan reported its first case on $26^{\text {th }}$ February; New Zeeland reported its first case on $28^{\text {th }}$ February 2020, while Australia reported its first case on $25^{\text {th }}$ January [32]. The number of cases in both Australia and New Zealand is still on the lower side depicting a unified, apolitical, clear, and effective response. Australia's COVID-19 patient recovery rate stands at $90 \%$ whereas New Zealand's recovery rate stands at roughly $75 \%$ [2]. On the other hand, Pakistan's patient recovery rate is almost 36.3\% [22]. Australia and New Zeeland adopted an aggressive approach, early and intensive lockdown with the implementation of stringent measures including border closure resulting in a steady fall in the number of daily new cases in both Australia and New Zealand [57].

More recently Pakistan has adopted a national strategy for test, trace, and quarantine (TTQ) to identify infection spread, focused clusters, and hotspots to enable targeted lockdowns and need-driven resource optimization at all levels [58]. Singapore and South Korea managed to contain COVID-19 through extensive testing without lockdown or major social disruption by maximizing all efforts to interrupt new transmission chains and keeping clusters under control $[59,60]$. The plan has been chalked out by federal and provincial governments for the imposition of smart lockdown based on 'tracking-tracing-screening' owing to the drastic effects of complete lockdown on the economy and an impoverished workforce. Absolute lockdown can only be effective in more stable economies such as China, the United States (USA), and Germany. In the USA the worst-hit country to-date, the government has ordered reopening in all fifty states with limited business activities while New York City, the epicenter of the COVID-19 outbreak in the USA, remaining closed for business [61].

Regulatory and ethical bodies in Pakistan approved passive immunization therapy for COVID 19 patients with plasma of recovered patients [12]. In USA FDA has approved for nationwide trials of convalescent plasma and hyperimmune globulin derived from the blood of recovered COVID patients [62].

There is a lack of public awareness about the virus in Pakistan. General public attitude regarding the severity of COVID-19 and its precautionary measures is not serious considering COVID-19 as hoax. Prevailing social stigma associated with positive cases and conspiracy rumors especially in rural areas abound in Pakistan are worsening the spread of the Coronavirus. The ill-preparedness of the poor resourced government and the resistance created by community dynamics, local and religious beliefs are making the containment of virus a tough challenge in Pakistan. A shortage of quarantine facilities, isolation units, and testing facilities in proportion to population has also hampered efforts to effectively contain the epidemic. Pakistan being a resourcelimited country with insufficient existing emergency preparedness and mechanism in place needs to reinforce national public health capabilities, infrastructures, aggressive disease surveillance systems and laboratory networks, and trained human capacity. After the passage of the $18^{\text {th }}$ amendment in 2010 country, health, and social protection were declared provincial subject with the federal government having the mandate of interprovincial coordination and broader health policy, among other responsibilities. There is a lack of coordination between the federal and provincial governments leading to weak disease surveillance and response mechanisms. Provinces with their health systems are taking independent decisions. The Pakistani leadership has remained divided on the scale and intensity of a lockdown due to the resulting negative impact on poor vulnerable class.

\section{Conclusion and Recommendations}

The COVID-19 pandemic has changed the world within four months. Government policies are jolted by COVID-19 shock with realization, everyone realizes that majority of the countries' spending has been a misplaced priority, and that health and the social sector should be the areas of utmost priority. Even though Pakistan might not enjoy such favorable conditions, a stable economy and easy to manage borders formulation and implementation of stringent policies will pull Pakistan out of this global health catastrophe that has claimed thousands of lives. However, within the available resources, the country has sufficiently raised the level of preparedness but still, Pakistan needs to ramp up testing across the country on war-footings keeping the huge population of Pakistan in mind.COVID-19 will have lasting health and economic effects beyond morbidity and mortality caused directly by the virus itself.

Pakistan needs to emphasize continue stratified risk assessment, a managing trinity of the health crisis, economic slide, and psychosocial impact through efficient resource management. The need for social distancing as a key and trusted step towards limiting humanto-human transmission of the disease centers on eliminating or keeping face-to-face interaction at a bare minimum. A vigilant check on the implementation of standard operating procedures (SOPs) for reopening under restrictions with mandatory use of face masks in public places and enforcement of social distancing is obligatory for containment and elimination of the epidemic. The social stigma and ostracization of the confirmed positive cases need to be discouraged. Societal rejection of people being tested positive with COVID-19 will lead to the addition of cases as associated stigma will discourage people from presenting themselves for testing, causing damage to the preventive measures in this concern all of the government and society's approaches can be made to work, it is time for a national unity. The need for effective community engagement and awarenessraising through print, social and electronic media to combat the virus is needed.COVID-19 response requires a strong comprehensive approach with interprovincial coordination and cross-sector timely decision making. Pakistan in spite of being a middle income country, is fighting COVID-19 through a robust and coordinated national response which is commendable.

\section{Author's Contribution}

$\mathrm{NN}$ involved in the conception and design of the study, literature review, data analysis and wrote the manuscript. SW, SD, and FD involved in manuscript editing. SUKN and NUK supervised the study. All authors read and approved the final manuscript.

\section{Competing Interests}

The authors declare that they have no competing interests.

\section{Funding}

None 


\section{References}

1. WHO (2020) Coronavirus disease 2019.

2. COVID-19 Dashboard by the Center for Systems Science and Engineering (CSSE) at Johns Hopkins University (JHU).

3. Readfearn G (2020) How did coronavirus start and where did it come from ? Was it really Wuhan's animal market?

4. Guo Y, Cao Q, Hong ZS, Tan YY, Chen SD, et al. (2020) The origin , transmission and clinical therapies on coronavirus disease 2019 (COVID-19) outbreak-an update on the status. Mil Med Res 7: 11.

5. Report of the WHO-China Joint Mission on Coronavirus Disease 2019 (COVID-19).

6. Coronavirus Symptoms (COVID-19) Pre-existing conditions (2020) Worldometer.

7. Pueyo T (2020) Coronavirus: Why You Must Act Now.

8. Sanche $\mathrm{S}$, Lin $\mathrm{YT}, \mathrm{Xu} \mathrm{C}$, Romero-Severson $\mathrm{E}$, Hengartner $\mathrm{N}$, et al. (2020) The Novel Coronavirus, 2019-nCoV, is Highly Contagious and More Infectious than Initially Estimated. medRxiv.

9. Coronavirus ( COVID-19) Update: FDA Continues to Facilitate Development of Treatments. FDA, USA.

10. Wetsman N (2020) FDA authorizes experimental drug remdesivir for emergency use in COVID-19 patients. The Verge.

11. Radcliffe S (2020) Here's Exactly Where We Are with Vaccines and Treatments for COVID-19. Health News.

12. Jamal S (2020) COVID-19 : Pakistani doctors get approval for plasma therapy clinical trial. Gulf News.

13. Agency A (2020) Pakistan's first COVID-19 patient recovers with plasma therapy. The Express Tribune.

14. Noreen N, Dil S, Ullah S, Naveed I, Khan NU, et al. (2020) Coronavirus disease ( COVID-19) Pandemic and Pakistan, Limitations and Gaps. University of New South Wales, Ubiquity Press.

15. Badshah SL, Ullah A, Badshah SH, Ahmad I (2020) Spread of Novel coronavirus by returning pilgrims from Iran to Pakistan. J Travel Med 27: 1-3.

16. Petersen HE, Baloch SM (2020) Pakistan coronavirus cam: 'No facilities, no humanity.'

17. World Asia (2020) Pakistan records 11 new coronavirus cases bringing the total tally to 18 .

18. Bhatti BMW (2020) Community transmission of coronavirus begins in Karachi. International The News.

19. EOC, Ministry of the National Health Services, Regulations \& Coordination National Emergency Operations Centre Table-1B: Details of Deaths Due to COVID-19 Ministry of the National Health Services, Regula.

20. Government of Pakistan, Ministry of Health services, Regulations and Coordination (2020) National Action Plan for Preparedness \& Response to Corona Virus Disease (COVID-19) Pakistan.

21. WHO (2020) Coronavirus Disease ( COVID-19).

22. Government of Pakistan (2020) COVID-19 Health Advisory Platform by Ministry of National Health Services Regulations and Coordination.

23. Coronavirus (COVID-19) Testing - Statistics and Research-Our World in Data. Our world In Data.

24. The Express Tribune, LIVE : Govt makes face masks compulsory in public as COVID-19 tally soars to 68,307 .
25. Health Department of Gilgit-baltistan, Government of Department govt of Gilgit-baltistan, GB sit report.

26. District Health Office Islamabad on Twitter; Recovered patients being notified are $10 \%$.

27. District Health Office Islamabad on Twitter; Total number of positive cases investigated today in \#lslamabad were 151 and 179 were investigated against today's.

28. Franki $R$ (2020) High rate of asymptomatic COVID-19 seen in cruise ship passengers. MD esge deramatolgy news.

29. He D, Zhao S, Lin Q, Zhuang Z, Cao P, et al. (2020) The relative transmissibility of asymptomatic COVID-19 infections among close contacts. Int J Infect Dis 94: 145-147.

30. Chema U (2020) New data shows abnormal increase in asymptomatic coronavirus cases. International The News.

31. Desk W (2020) SAPM Mirza says it is mandatory for people to wear masks now.

32. Worldometer (2020) COVID-19 Coronavirus Pandemic.

33. Gandhara (2020) Pakistan Deploys Military To Impose Coronavirus Lockdown.

34. Population, Labour Force and Employment.

35. Slater J, Masih N (2020) The largest lockdown in the world is ending. India is bracing for what comes next. The Washington Post.

36. Ritchie $H$, Ortiz-Ospina E, Beltekian D, Mathieu E, Hasell J, etal. (2020) Coronavirus (COVID-19) Deaths, Statistics and Research, Our World in Data.

37. Population ages 65 and above (\% of total population). Trading Economics.

38. Asian Development Outlook 2020 April 2020, What Drives Innovation In Asia? The Impact of the Coronavirus Outbreak-An Update.

39. Mehtab H (2020) COVID-19 e ects : Pakistan estimates 0.8 to $1.3 p c$ loss to GDP growth. International The News.

40. The World Bank In Pakistan.

41. Duffin E (2020) Impact of the coronavirus pandemic on the global economy-Statistics \& Facts. Statista.

42. Zulfiqar Shah (2020) Labour Cost Benefits. Dawn.com.

43. Akhtar S, Shah H (2020) Framework for SME Sector Development in Pakistan.

44. Pakistan and ADB Poverty Data. Asian Development Bank.

45. Raza S (2020) Coronavirus forecast to render $18.5 \mathrm{~m}$ jobless in Pakistan. The Express tribune.

46. Giles Clarke (2020) COVID-19: impact could cause equivalent of 195 million job losses, says ILO chief. UN news.

47. Using cash payments to protect the poor in Pakistan. World economic forum (2020).

48. Pakistan Economic Survey 2018-19. Health and Nutrition.

49. PPI (2020) Health spending less than one percent of GDP for decades. Pakistan Today.

50. Armocida B, Formenti B, Ussai S, Palestra F, Missoni E (2020) The Italian health system and the COVID-19 challenge. Lancet Public Health 5: e253.

51. Abir M, Cutter C, Nelson C (2020) COVID-19 : A Stress Test for A US Health Care System Already Under Stress. Health Affairs. 
52. Govt relaunches guidelines for rational use of PPE. ARY news.

53. Mantovani C (2020) Over 90,000 health workers infected with COVID-19 worldwide : nurses group. Reuters.

54. What's needed now to protect health worker: WHO COVID-19 briefing. World Economic Forum.

55. Mitchell Ge (2020) Nurses among confirmed deaths from COVID-19 around the world. Nurses Times.

56. COVID-19: One in four doctors off sick or in isolation. Itv News.

57. Graham C (2020) "You can't compare": New Zealand looks on Australia's loose lockdown with envy and horror. The Guardian.
58. Govt to launch 'National TTQ Strategy' to contain COVID-19. Daily times.

59. Lee VJ, Chiew CJ, Khong WX (2020) Interrupting transmission of COVID-19: lessons from containment efforts in Singapore. J Travel Med 27: 1-5.

60. Bicker L (2020) Coronavirus in South Korea : How 'trace, test and treat' may be saving lives. BBC News.

61. Mervosh BS, Lee JC, Gamio L, Popovich N, May U (2020) See How All 50 States Are Reopening. The Newyork Times.

62. Rogers A (2020) Trials of Plasma From Recovered COVID-19 Patients Have Begun. Wired. 